\title{
MENTAL HEALTH LEGISLATION: DOES IT PROTECT THE RIGHTS OF PEOPLE WITH MENTAL HEALTH PROBLEMS?
}

\section{Barbara Simpson, Jennifer Chipps}

\section{INTRODUCTION}

The International Federation of Social Work places a concern with human rights and social justice at the core of its definition of social work. Social work values are based on "respect for the equality, dignity and worth of all people" (IFSW, 2000), and social work practice has a special concern for vulnerable and oppressed people. People with mental health problems are amongst the most vulnerable members of society and in South Africa they comprise a considerable proportion of our society. According to the South African Stress and Health Survey (Herman, Steyn, Seedat, Heeringa, Moonal \& Williams, 2009), the lifetime prevalence for any mental health problems in South Africa is $30.3 \%$ and neuropsychiatric disorders rank third in their contribution to the burden of disease in South Africa (Bradshaw, Norman \& Schneider, 2007).

The treatment of people with mental health problems worldwide has been marked by abuse and neglect (Hamber \& Rock, 1993). Some of the human rights violations of persons with mental disorders include a lack of access to essential health care and treatment, inappropriate or forced admission to psychiatric facilities without the necessary protection, poor living conditions in psychiatric institutions, unnecessary or inhumane treatment, inappropriate use of seclusion and restraints, abuse from personnel or fellow patients during treatment, isolation from family and society, discrimination and loss of basic civil rights (Hunt \& Mesquita, 2006). Mental health care has undergone significant changes in post-apartheid South Africa and the Mental Health Care Act No. 17 of 2002 (promulgated in December 2004) was an attempt to transform the mental health care system from one which focused largely on custodial care and protection to one based on human rights.

This article explores the extent to which South African legislation protects the rights of people with mental health problems and examines some of the challenges in implementing legislation.

\section{METHODOLOGY}

This purpose of the study was to conduct a desktop review of published research on the South African legislation in respect of mental health care to answer three questions:

1. How has mental health care legislation historically protected the rights of people with mental health problems prior to 2002 ?

2. How does the Mental Health Care Act, No. 17 of 2002 (the Act) protect the rights of people with mental health problems?

3. Is the Act being implemented in such a way as to protect the rights of people with mental health problems?

The terms mental illness, disorder or disability, psychiatric illness, disorder or disability, and mental health problems are used interchangeably in the literature. These terms, as well as the act, legislation, rights and South Africa were used to search the Sabinet, Pubmed, Academic Search Complete databases. To address questions two and three, only articles from 2002 onwards were used (the date of the Act). This review focuses only on mental health problems and excludes intellectual disability. 


\section{LITERATURE REVIEW}

\section{Question 1: How has mental health legislation historically protected the rights of people with mental health care problems prior to 2002?}

South Africa has a long-established system of mental health care dating back to colonial times. The first hospital for "mentally deranged patients" was established in Cape Town in 1711 (Emsley, 2001). By 1846 facilities in Cape Town were considered to be insufficient and an island colony, Robben Island - later to become famous as the prison for political detainees during apartheid - was established to care for "lepers, lunatics and other chronically ill people" (Emsley, 2001:382). By 1912500 mental patients were housed on Robben Island. Other large "lunatic asylums" were also built in Pietermaritzburg (Town Hill), Grahamstown (Fort England), Pretoria (Pretoria Lunatic Asylum) and Cape Town (Valkenburg). By 1910 3,624 patients were being cared for in eight mental hospitals and by 195514,000 patients were cared for in 24 mental hospitals (Emsley, 2001).

\section{The Mental Disorders Act, No. 38 of 1916}

This was the first attempt to legislate for the care of people with mental health problems. This Act unified the control of mental hospitals under a Commissioner of Mental Hygiene (Minde, 1975). The main thrust of mental health services in the period following this was the provision of hospital beds to accommodate the growing number of patients and the focus was on custodial care.

\section{The Mental Health Act, No. 18 of 1973}

The 1973 Act replaced the Mental Disorders Act. The name of this Act, with the emphasis on mental health rather than mental disorders, heralded a more positive, forward-looking attitude towards people with mental health problems (Minde, 1975). It was seen as an improvement on the Mental Disorders Act of 1916 (Minde, 1975), but the rights of people with mental health problems were still seriously compromised.

This was exacerbated by the apartheid policies introduced by the Nationalist government in 1948. In the discriminatory system that was developed, mental health services were primarily for whites in urban areas and followed patterns of racial segregation and inequality (Pillay \& Lockhat, 1997). Psychiatric services were concentrated in urban tertiary psychiatric hospitals and patients from rural areas were admitted to hospitals that were great distances from their homes, family and employment area. Little or no care existed in the community. Patients who entered the health system became powerless, alienated and stigmatised by the system (Burns, 2008). The focus of mental health services in South Africa (and indeed, in most of the world prior to 2000) was on the welfare and safety of the community and this was given priority over the human rights of people with mental health problems (Burns, 2008).

The certification process under the 1973 Act was open to abuse. Suspecting a person of suffering from a mental disorder was sufficient grounds for certification and very often ulterior motives including jealousy, personal prejudices and vendettas were behind the certification of patients. The process of certification was also used for political reasons to detain and silence protestors. Once certified, patients could do nothing and had no way of appealing these decisions or accessing help from the courts (Burns, 2008).

Internationally South African psychiatry was condemned for its lack of opposition to apartheid policies, and in some cases complicity, in setting up separate services for the different race groups. A report compiled by the American Psychiatric Association in 1978 following the inspection of psychiatric services in South Africa found psychiatric care for black people 
"disgustingly" substandard to that provided for white people. They also ascertained that these deplorable medical practices had caused needless deaths of black patients and that "apartheid has a destructive impact on the families, social institutions, and the mental health of black South Africans" (American Psychiatric Association, 1983 cited in Emsley, 2001:384).

\section{Question 2: How does the Mental Health Care Act, No. 17 of 2002 (the Act) protect the rights of people with mental health problems?}

In 1994 South Africans went to the polls and elected their first democratic government and since then there has been a flurry of White Papers and new legislation aimed at redressing the abuses of the past. The White Paper for Health (Department of Health, 1997) recommended that mental health services should be comprehensive and community based and integrated with other health services. In 2002 the Mental Health Care Act, No. 17 of 2002 was passed in the National Assembly of South Africa and the National Council of Provinces and replaced the Mental Health Act. This had been preceded by an extensive process of consultation with stakeholders such as consumer groups and families, non-governmental institutions, universities, practitioners and government departments. The Act was finally promulgated in December 2004.

This Act aims "to provide for the care, treatment and rehabilitation of persons who are mentally ill; to set out different procedures to be followed in the admission of such persons; to establish Review Boards in respect of every health establishment; to determine their powers and functions; to provide for the care and administration of the property of mentally ill persons; to repeal certain laws; and to provide for matters connected therewith" (Mental Health Act, No. 17 of 2002).

As far as the human rights of people with mental health problems are concerned, the same rights that apply to all people apply equally to those with mental health problems. The Act, however, emphasises rights and devotes a whole chapter (Chapter 3) to the rights and duties relating to mental health care users. These are also in accordance with international standards as stated in Resolution 46/119 of the United Nations General Assembly (1991) "Principles for the protection of persons with mental health problems and for the improvement of mental health care" and the World Health Organisation's (1996) "Guidelines for the Promotion of Human rights of persons with mental disabilities". The guiding principles of these documents serve to ensure that decisions are taken in "the best interests" of users and in the "least restrictive environment" (Freeman, 2002:5). Relevant sections of the Act are highlighted in Table 1.

Apart from entrenching the rights of people with mental disabilities, the Act also contains a number of specific provisions which are aimed at protecting these rights and reducing the stigma attached to mental disability. These are outlined below. 


\section{TABLE 1 \\ RIGHTS AND DUTIES RELATING TO MENTAL HEALTH \\ CARE USERS UNDER THE ACT}

Sect 8(1): The person, human dignity and privacy of every mental health care user must be respected.

Sect 8(2): Mental health care users must be provided with care, treatment and rehabilitation services that improve their mental capacity to develop to their full potential and facilitate their integration into community life.

Sect 9: Except where it is not possible due to the mental health user's mental state, people should give consent for their care, treatment and rehabilitation.

Sect 10: This section deals with unfair discrimination against people with mental disabilities and states that care, treatment and rehabilitation services must be of the same standard as other health care services.

Sect 11: Mental health care users are to be protected from exploitation and degrading treatment, and from forced labour. It also states that care, treatment and rehabilitation may not be used as a punishment or for the convenience of other people.

Sect 13: Mental health care users have the right to confidentiality.

Sect 14: Mental health care users have the right to intimate adult relationships.

Sect 15: Mental health care users have the right to representation.

Sect 16: Mental care users must receive a discharge report for the purposes of receiving care, treatment and rehabilitation.

Sect 17: Mental health care users must be informed of their rights before being receiving care, treatment and rehabilitation.

\section{Terminology}

The 2002 Act introduced new terms for patients, who were now to be called "mental health care users". All professional designations of people working in the mental health sector were collapsed into one new category, "the mental health care practitioner". According to the Act, a mental health care practitioner may be a registered psychiatrist or medical practitioner, or a nurse, occupational therapist, psychologist or social worker trained to provide mental health care services.

While some might say this is purely a matter of semantics (Szabo, 2006), it was an attempt to move away from the hurtful labels that set apart people with mental health problems. As Carling (1994, in Perkins \& Pepper, 2001) pointed out, language can be used to separate people by defining the needs of people with a particular label as fundamentally different from those of other citizens.

It was also hoped that by widening the definition of who could assist people with mental health problems, greater access to services would be facilitated. An important part of the definition is the word "trained", so ensuring that mental health services are carried out by those who are competent and qualified to do so (Freeman, 2002). 


\section{Integration of mental health care into primary health care}

Treating mental health problems as any other illness and within the same health system should reduce the stigma associated with mental health problems. Mental health care policy should aim to integrate comprehensive community-based mental health care services at the primary health care level in the least restrictive environment. The objective is "to make mental health services as much part of general health care as other health areas" and to replace custodial care with community-oriented alternatives for all but a small minority of people with mental health problems (Freeman, 2002:7).

The Act addresses this in two specific ways. Section 3(a)(iii) of the Act makes provision for the integration of mental health services into the general health environment. Section 34 of the Act makes provision for involuntary and assisted mental health care users to first be admitted for 72 hours observation at a local general hospital. Burns (2008), Moosa and Jeenah (2010) and Ramlall, Chipps and Mars (2010) identify several good reasons for this. Medical causes for behavioural or psychiatric disturbances can be ruled out and many mental health care users, especially those with acute trauma or substance abuse problems, can recover and can be discharged with 72 hours or at least improve sufficiently to give consent for voluntary treatment. Increasing access to care and the availability of local services thus reduces the need for premature or unnecessary transfers to psychiatric hospitals.

\section{Review boards}

Chapter Four of the Act is devoted to Review Boards and the Act makes provision for Mental Health Review Boards to be set up in each establishment which provides mental health care, treatment and rehabilitation (Section 18). In terms of Section 19, these Boards have an oversight function: they monitor and control admissions to care establishments, they inspect such establishments, and further hear representations and complaints from mental health care users and their families as well from staff. The Boards also have a role to play when a person may require treatment but will not give consent. Under the previous legislation a magistrate could order that such a person be admitted to a psychiatric unit. Now the head of a hospital may admit the person after an examination by at least two professionals. This decision is then referred to the Review Board, which must ensure that it is in the best interests of the person concerned to be admitted. Review Boards thus provide a mechanism to ensure that the rights of mental health care users are protected.

\section{Question 3: Is the Act being implemented in such a way as to protect the rights of people with mental health problems?}

Overall there has been a shortage of resources to implement the key components of the Act, resulting in mental health care users not having easy access to care or receiving care of poor quality. This can be seen in the lack of success in meeting the specific provisions of the Act to protect the rights of people.

\section{Failure of psychiatric hospitals to provide adequate care}

There is evidence that funding for psychiatric hospitals is not increasing at the same rate as for general hospitals and that they are failing to provide adequate care. On average, psychiatric hospitals received a third of the increase to general hospitals over a five-year period (Burns, 2010). There continues to be a shortage of beds at specialist psychiatric hospitals (Van Heerden, Hering, Dean \& Stein, 2008) and a lack of specialised services within psychiatric hospitals. Burns (2010) reported that in KwaZulu-Natal there are only four in-patient child and 
adolescent beds, 10 psychogeriatric beds and no dedicated beds for dual diagnosis, eating disorders, first-episode psychosis and neuropsychiatry patients.

There have also been instances where the system has completely failed to provide mental health care for people with severe mental health problems who require hospitalisation. In a study by Lucas, Stevenson and Mercy (2005), more than 50\% of patients who participated in the study reported experiences of abuse from staff and patients. In addition, they found that almost $44 \%$ of patients were frightened to stay in the hospital for treatment (Lucas et al., 2005). This is further highlighted by the abuses that occurred at a specialist psychiatric hospital in KwaZulu-Natal in 2005 and which necessitated an investigation by a Commission of Enquiry. The findings of the commission confirmed media allegations of human rights abuses at the hospital. In addition, the commission identified a range of systemic defects. These included weak management over a long period of time, the absence of a hospital board, inadequacies in the physical layout and quality of facilities, patients abusing staff, staff reporting on duty under the influence of alcohol, a high rate of absenteeism, a shortage of staff, lack of discipline, evidence of racism, nepotism and favouritism as well as strained relations between the management and labour unions (Mkhize, 2007).

\section{The integration of mental health services with general health services}

Integrating mental health services into the general health service system has not been easy. Writing in the context of the Western Cape, Van Heerden et al. (2008) identified a number of obstacles to managing mental health users in the general health system. They pointed out that it is extremely difficult to manage acutely suicidal and disruptive psychotic patients in medical wards together with frail medically ill people. In addition, the absence of safe observation facilities and the limited availability of psychotropic medicines hampered the effective care of mental health care users. Limited staff numbers, the lack of competencies in existing staff and staff prejudices towards the treatment of mental health users were further challenges.

Similarly, Burns (2008) warned that most institutions were experiencing problems in providing 72-hour observations and that this was leading to sub-optimal care. Mental health care users were either highly sedated, making observation difficult or were inadequately sedated, making their management in a general ward very difficult. Inadequate facilities and poorly skilled health workers also contributed to the problems. A study by Ramlall et al. (2010) confirmed that many problems existed in respect of 72-hour observation in KwaZulu-Natal. Sixty-three percent of designated hospitals reported that they did not have appropriate or adequate facilities to provide the psychiatric services as required by the Act. Hospitals reported a lack of beds, staff and appropriate seclusion rooms to accommodate mental health care users.

The shortage of resources also means that mental health care users may not have easy access to care. Burns (2010), for example, reported that KwaZulu-Natal had only a quarter of the number of acute beds required to comply with the national norm of 28 beds per 100,000 population.

\section{Review Boards}

Review Boards are intended to play a vital role in ensuring that the human rights of mental health care users are protected. Establishing such boards and providing them with adequate space and administrative support has been slow and it was only in 2007, for example, that standard operating procedures for Review Boards in KwaZulu-Natal were published. Ramlall et al. (2010) found that visits by Review Boards to psychiatric facilities were infrequent and generally not found to be useful. Even when visits were found to be useful, this usefulness was 
hampered by the limited powers of the Boards to improve funding and infrastructure development.

\section{Establishing community based mental health services}

A strong system of community-based psychiatric services is necessary to ensure adequate care, treatment and rehabilitation, but as Moosa and Jeenah (2008) pointed out, new services have not been developed and existing ones have not been strengthened.

In an audit of services in Gauteng, Moosa and Jeenah (2008) found that primary health care professionals played no role in the management of mentally ill patients. Services were provided by specialist psychiatrists, registrars and psychiatric nurses with minimal, if any, support from psychologists, occupational therapists and social workers. Their visits to the primary health care facility ranged from one day per week to one day per month, and the average waiting time to see a psychiatrist was six months. Mental health care users had follow up appointments on average every four months. In short, the primary health care facilities were totally unable to provide a comprehensive service to mental health care users.

The situation is not entirely bleak, however, with Van Deventer, Couper, Wright, Tumbo and Kyeyune (2008) finding a degree of satisfaction among patients attending clinics in North West province. Despite complaining about long waiting times and the need for more staff (especially doctors and other professionals such as psychologists and social workers), patients generally felt that they were getting good care and being treated well by the nurses, who were providing the bulk of the services.

A strong system of primary health care services and community-based services is also required to support de-institutionalisation and the integration of previously institutionalised mental health care users with severe and chronic psychiatric problems into the primary health care system. De-institutionalisation was intended to humanise care for people with mental health problems, and to stem the human rights abuses that were taking place in large mental hospitals that were isolated from society (Hamber \& Rock, 1993). The international experience with deinstitutionalisation has not been entirely positive, however, with some writers (Lamb, 1985) suggesting that de-institutionalisation resulted in a violation of human rights. Without adequate community support, people with mental health problems may experience increased anxiety, depression and deprivation, and may be more at risk of becoming homeless (Lamb, 1985).

South Africa does not appear to have heeded the lessons learned from the international experience. Van Heerden et al. (2008) point out that the pressure on large psychiatric hospitals to discharge patients was not accompanied by increased funding for community services, while the lack of community services has already been discussed in this article.

The challenges of finding suitable alternate placements for mental health care users who are considered ready for discharge from psychiatric hospitals have also been highlighted in the literature. Janse van Rensburg (2005) found that only nine of a possible 27 patients considered ready for discharge at a Gauteng facility were successfully placed in the community after one year. Difficulties included some families who could refuse to accept their family members because of their limited emotional and physical resources, as well as some NGOs who had admission criteria that excluded particular groups of people based on age. Similarly, Krüger and Lewis (2011) found it almost impossible to place the lower-functioning patients with behaviour problems as community facilities simply did not have to expertise to deal with these patients. 


\section{DISCUSSION}

Kaliski (2002) commented that any new mental health care legislation usually reflects an idealistic desire to be more humane and to protect those with mental health problems, and indeed the Mental Health Care Act, No. 17 of 2002 is "a commendable attempt to ensure that the rights of mentally ill individuals are preserved" (Kaliski, 2002:8). It is clear that the Act provides an excellent framework for mental health services and that it actively seeks to protect the rights of people with mental health problems. It is also clear that there remain enormous challenges in the implementation of Act, which results in a situation in which the rights of people with mental health problems are not respected and upheld. This article has identified a myriad of systemic weaknesses that impact negatively on the mental health care, treatment and rehabilitation.

One of the primary reasons for the challenges in implementing the Act is the fact that the promulgation of the Act was not accompanied by required provision of resources by national or provincial government. Janse van Rensburg (2007) commented that it is clear that the financial considerations of the Act were not considered and that in many instances services simply continued as before. Similarly, Petersen, Bhana, Campbell-Hall, Mjadu, Lund, Kleintjies, Hosegood, Flisher and the Mental Health and Poverty Research Programme Consortium (2009) expressed concern that a lack of resources has hampered the delivery of mental health services, especially in rural areas. A major problem has been the low priority given to mental health and the inability of planners to translate the principles enshrined in the Act into implementable policies.

A further issue concerns the rights of families and community members when services to mental health care users fail. Inadequate care at district hospitals not only violates the rights of mental health care users to adequate care and treatment, but it also puts other health care users at risk. The lack of community services for families and the burden of caring for a family member with psychiatric problems takes it toll on the family and there is a risk that the human rights of both the family and the mental health care user may be violated. Swartz, Breen, Flisher, Joska, Corrigal, Plaatjies and McDonald (2006) point out that in some cases a family member has to leave work to care for the ill person, thus placing a considerable financial burden on the family. It has also been noted that the person's disability grant may be used by the family for purposes other than to support the individual (Mkhize \& Kometsi, 2008). A study by Kotze, Van Delft and Ross (2010) reviewed the needs of outpatients with schizophrenia. Both the patients and family care givers needed help in managing the illness and their lives, and they identified the need for psychosocial and after-care programmes such as support groups. Caregivers were found to be a particularly vulnerable group, with $92 \%$ of them reporting that their health had been affected (Kotze et al., 2010).

People with mental health problems in South Africa are subject to "multiple levels of inequality and discrimination" (Burns, 2009). South Africa has high rates of poverty, unemployment and inequality. There is evidence that suggests that people living in poverty and unemployment are at increased risk of developing mental health problems (Burns, 2009), but it is also these very factors that impede access to health care.

Because of their work with families in communities and their commitment to intervening "at points where people interact with their environments" (IFSW, 2000), social workers are ideally placed to play a major role in helping to entrench the rights of people with mental health problems. Very specifically, social workers should be involved in the following aspects:

- Assist with the early identification of mental health problems and referral to appropriate resources; 
- Raise public awareness about the treatment, care and rehabilitation of people with mental health problems;

- Work with consumer groups to advocate for improved services for people with mental health problems;

- Monitor the care, treatment and rehabilitation of individual clients and report human rights abuses immediately to the authorities.

\section{CONCLUSION}

Empirical evidence is now mounting that serious challenges remain and that the lack of resources has dire consequences in terms of the human rights of people with mental health problems. In particular, the rights of mental health care users to be provided with care, treatment and rehabilitation services that improve their mental capacity to develop to their full potential and facilitate their integration into community life and to care, treatment and rehabilitation services that are of the same standard as other health care services are being violated.

\section{REFERENCES}

BETANCOURT, O.A. \& HERRERA, M.M. 2010. Editorial. Community rehabilitation for schizophrenia patients: is it feasible in South Africa? South African Journal of Psychiatry, 16(3):66-68.

BOTHA, U.A., KOEN, L., JOSKA, J.A., HERING, L.M. \& OOSTHUIZEN, P.P. 2010. Assessing the efficacy of a modified assertive community-based treatment programme in a developing country. BMC Psychiatry, 10:73. doi:10.1186/1471-244X-10-73. [Online] Available: http://www.biomedcentral.com/1471-244X/10/73. [Accessed: 05/06/2011].

BRADSHAW, D., NORMAN, R. \& SCHNEIDER, M. 2007. Editorial. A clarion call for action based on refined DALY estimates for South Africa. South African Medical Journal, 97:438-440.

BURNS, J.K. 2008. Implementation of the Mental Health Care Act (2002) at district hospitals in South Africa: Translating principles into practice. South African Medical Journal, 98(1):46-51.

BURNS, J.K. 2009. Mental health and inequity: A human rights approach to inequality, discrimination and mental disability. Health and Human Rights, 11(2):19-31.

BURNS, J.K. 2010. Mental health services funding and development in KwaZulu-Natal: a tale of inequity and neglect. South African Medical Journal, 100(10):62-66.

DEPARTMENT OF HEALTH. 1997. White Paper for the Transformation of the Health System in South Africa. Pretoria: Government Gazette.

EMSLEY, R. 2001. Focus on psychiatry in South Africa. British Journal of Psychiatry, 178:382-386.

FREEMAN, M. 2002. New mental health legislation in South Africa - principles and practicalities: A view from the Department of Health. South African Psychiatry Review, $5(3): 4-8$.

HAMBER, B. \& ROCK, B. 1993. Mental health and human rights: In search of context, consequence and effective care. Rethinking Rights, 1:72-91. [Online] Available: http://www. csvr.org.za/index.php?option=com_content\&view=article\&id=1664\%3Amental-health-and-humanrights-in-search-of-context-consequence-and-effective-care \&Itemid=2 [Accessed: 15/04/2011]. 
HERMAN, H.A., STEYN, D.J., SEEDAT, S., HEERINGA, S.G., MOONAL, H. \& WILLIAMS, D.R. 2009. The South African Stress and Health (SASH) study: 12 month and lifetime prevalence of common mental disorders. South African Medical Journal, 99(5):339344.

HUNT, P. \& MESQUITA, J. 2006. Mental disabilities and the human right to the highest attainable standard of health. Human Rights Quarterly, 28 (2):332-56.

IFSW. 2000. Definition of social work [Online] Available: http://www.ifsw.org/ f38000138.html. [Accessed: 15/04/2011].

JANSE VAN RENSBURG, A.B.R. 2007. A framework for current public mental health care practice in South Africa. African Journal of Psychiatry, 10(4):205-209.

JANSE VAN RENSBURG, B. 2005. Community placement and re-integration of service users from long term mental health care facilities. South African Psychiatry Review, 8(3):100-103.

KALISKI, S. 2002. Commentary. South African Psychiatry Review, 5:8.

KOTZE, A.M.E., VAN DELFT, W.F. \& ROSS, J.L. 2010. Continuity of care of outpatients with schizophrenia in Pretoria. South African Journal of Psychiatry, 16(3):80-83.

KRÜGER, C. \& LEWIS, C. 2011. Patient and social work factors related to successful placement of long-term psychiatric in-patients from a specialist psychiatric hospital in South Africa. African Journal of Psychiatry, 14:120-129.

LAMB, R.H. 1985. The homeless mentally ill. Washington: American Psychiatric Association.

LUCAS, M., STEVENSON, D. \& MERCY, W. 2005. Institutional victimisation in postapartheid South Africa. South African Journal of Psychiatry, 11(3):90-94.

MINDE, M. 1975. History of mental health services in South Africa. Part VII. Services since union. South African Medical Journal, 49(11):405-409.

MKHIZE, D.L. 2007. Human rights abuses at a psychiatric hospital in KwaZulu-Natal. South African Journal of Psychiatry, 13(4):137-142.

MKHIZE, N. \& KOMETSI, M.J. 2008. Community access to mental health services: Lessons and recommendations. In: BARRON, P. \& ROMA-REARDON, J. (eds) South African Health Review. Health Systems Trust. [Online] Available: http://www.hst.org.za/ publications/south-african-health-review-2008. [Accessed: 15/04/2011].

MOOSA, M.Y.H. \& JEENAH, F.Y. 2008. Community psychiatry: an audit of the services in Southern Gauteng. South African Journal of Psychiatry, 14(2):36-43.

MOOSA, M.Y.H. \& JEENAH, F.Y. 2010. A review of the applications for involuntary admissions made to the mental health review boards by institutions in Gauteng in 2008. South African Medical Journal, 16(4):125-130.

PERKINS, R.E. \& PEPPER, J.M. 2001. Exclusive language. In: MASON, T., CARLISLE, C., WATKINS, C. \& WHITEHEAD, E. (eds) Stigma and social exclusion in health care. London: Routledge.

PETERSEN, I., BHANA, A., CAMPBELL-HALL, V., MJADU, S., LUND, C., KLEINTJIES, S., HOSEGOOD, V., FLISHER, A.J. \& THE MENTAL HEALTH AND POVERTY RESEARCH PROGRAMME CONSORTIUM. 2009. Planning for district mental health 
services in South Africa: a situational analysis of a rural district site. Health and Policy Planning, 24(2):140-150.

PILLAY, A.L. \& LOCKHAT, M.R. 1997. Developing community mental health services for children in South Africa. Social Science and Medicine, 45(10):1493-1501.

RAMLALL, S., CHIPPS, J. \& MARS, M. 2010. Impact of the South African Mental Health Care Act, No 17 of 2002 on regional and district hospitals designated for mental health care in KwaZulu-Natal. South African Medical Journal, 100(10):667-670.

REPUBLIC OF SOUTH AFRICA. 1973. The Mental Health Act, No 18 of 1973. [Online] Available: http://www.kznhealth.gov.za/mentalact1973.pdf. [Accessed: 12.04/2011].

REPUBliC OF SOUTH AFRICA. 2002. The Mental Health Care Act, No 17 of 2002. [Online] Available: http://www.info.gov.za/view/DownloadFileAction?id=68051. [Accessed: $12 / 04 / 2011]$.

SWARTZ, L., BREEN, A., FLISHER, A., JOSKA, J., CORRIGALL, J., PlAATJIES, L. \& McDONALD, D.A. 2006. How depressing: poverty, mental health and municipal services in South Africa. Municipal services project. Occasional papers No 12. [Online] Available: http://www.municipalservicesproject.org/sites/default/files/PapersNo12_0.pdf. [Accessed: 15/04/2011].

SZABO, C.P. 2006. Editorial. The Mental Health Care Act: challenges and opportunities. South African Psychiatry Review, 9(1):1-5.

UNION OF SOUTH AFRICA. 1916. The Mental Disorders Act, No 38 of 1916. Uncertified copy available at South African National Legislation Index. [Online] Available: http://www.legalb.co.za/SA/SA-Nat-List-Date-1916.html. [Accessed: 15/04/2011].

UNITED NATIONS. 1991. Principles for the protection of persons with mental illness and the improvement of mental health care. Resolution 46/119 of 17 December 1991. [Online] Available: http://www2.ohchr.org/english/law/principles.htm. [Accessed: 15/04/2011].

VAN DEVENTER, C., COUPER, I., WRIGHT, A., TUMBO, J. \& KYEYUNE, C. 2008. Evaluation of primary mental health care in North West province - a qualitative view. South African Journal of Psychiatry, 14(4):136-140.

VAN HEERDEN, M.S., HERING, L., DEAN, C. \& STEIN, D. 2008. Providing psychiatric services in general medical settings in South Africa: mental health-friendly services in mental health-friendly hospitals. South African Journal of Psychiatry, 14(1):4-6.

WORLD HEALTH ORGANISATION. 1996. Guidelines for the promotion of human rights of persons with mental disabilities. [Online] Available: http://www.who.int/mental_health/ policy/legislation/guidelines_promotion.pdf [Accessed: 15/04/2011].

Dr Barbara Simpson, School of Social Work and Community Development; Ms Jennifer Chipps, School of Nursing, University of KwaZulu-Natal, Durban, South Africa. 